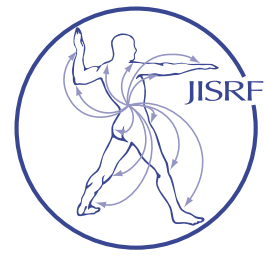

\title{
Manipulation Rate Is Not Increased After Customized Total Knee Arthroplasty
}

\author{
Kay $A^{1}$, Kurtz $W^{2}$, Martin $G^{3}$, Huber $B^{4}$, Tait $R^{5}$, Clyburn $T^{1}$
}

\section{ABSTRACT}

Background: Manipulation under anesthesia (MUA) is a standard treatment for arthrofibrosis after total knee arthroplasty (TKA), with reported rates of 1.5-6\%. Customized TKA may have better outcomes by matching individual patient anatomy. However, a previous study reported an unacceptably high rate of MUA for customized TKAs. This study reports the incidence of MUA in a large cohort of second generation customized TKAs.

Methods: Data was collected prospectively on 360 2nd generation ConforMIS iTotal cruciate retaining TKAs. MUA was performed for clinically significant arthrofibrosis. Range of motion (ROM) and New Knee Society Scores (KSS) were evaluated at regular intervals for two years.

Results: 11/360 (3.05\%) knees underwent MUA. ROM overall improved from $115^{\circ}$ to $125^{\circ}$, and from $112^{\circ}$ to $122^{\circ}$ in patients undergoing MUA. KSS objective and functional scores in MUA patients increased from 57 to 98 and 41 to 90 , respectively, and in the entire cohort increased from 65 to 96 and 45 to 86 at 2 years $(\mathrm{p}<0.05)$. No MUA patients underwent revision surgery.

Discussion and Conclusion: Customized TKA with second generation ConforMIS iTotal implants results in a MUA rate consistent with the literature for all designs. Additionally, patients exhibit significant increases in ROM and Knee Society Scores.

\section{BACKGROUND}

Arthrofibrosis can occur after total knee arthroplasty (TKA), with an incidence reported of 1-13\%. [1] Manipulation under anesthesia (MUA) is a common first-line treatment for stiffness after TKA. The incidence of patients undergoing MUA after a TKA has been reported between 1.5-6\%. [2-7] It is often recommended that MUA be done within 6-12 weeks of surgery if possible in order to achieve optimal gains in range of motion. $[\underline{1}, \underline{2}, \underline{4}, \underline{5}, \underline{8}-\underline{10}]$ MUA has been shown to be effective at increasing range of motion, with gains of $33^{\circ}$ persisting at long-term follow-up. [11] These gains have been shown to be similar to open or arthroscopic release. However, patients who undergo MUA have a significantly higher rate of eventual revision surgery, with an odds ratio of 2.43 in a review of a large national database. []ㅡ MUA is generally considered safe, although low rates of fracture, wound dehiscence, patellar tendon avulsions, quadriceps strain or rupture, hemarthrosis, heterotopic ossification, and pulmonary embolism have been reported. [12, $\underline{13}]$

Risk factors for arthrofibrosis include decreased preoperative range of motion, higher complexity of surgery (history of trauma, length of surgery), and history of prior sur-

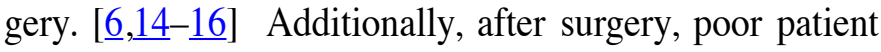

Keywords: total knee arthroplasty, manipulation under anesthesia, customized total knee arthroplasty, Arthrofibrosis, outcomes, complications

Level of Evidence: AAOS Therapeutic Level IV

Educational Value \& Significance: JISRF Level B 
motivation, immobility, delay in starting rehabilitation, poor pain tolerance, and infection can contribute to development of arthrofibrosis. $[\underline{10}, \underline{17}, \underline{18}]$

Prosthesis design has been implicated as a possible contributor to arthrofibrosis, although overall results are mixed. Several studies have compared cruciate-retaining (CR) versus posterior stabilized (PS) prostheses, with some finding decreased range of motion with CR designs, but others showing no significant difference. [ㄴ, 19-21] U1tracongruent TKA's have also been shown to have similar rates of MUA as compared to conventional designs. [22]

A recent prospective evaluation has also reported that patients undergoing CR TKA with a patient-specific design have a significantly higher rate of postoperative stiffness and need for manipulation versus matched controls [23]. In the patient-specific design group, the mean range of motion from flexion to extension was $3-98^{\circ}$ postoperatively, versus $2-111^{\circ}$ in the posterior stabilized controls, and $2-117^{\circ}$ in the cruciate-retaining controls. Of patients receiving the patient-specific implant, 6/21 underwent MUA, versus 0/53 in the control group. [23] Given these results, the present study seeks to investigate the incidence of MUA in a large cohort of knees implanted with a newer generation of the patient-specific CR design.

\section{METHODS}

The study protocol was reviewed and approved by the institutional review board. Data was collected prospectively at 9 institutions on 360 cemented, total knee arthroplasties performed using the cruciate-retaining iTotal implant (ConforMIS, Billerica, Massachusetts). The ConforMIS iTotal CR has evolved since its genesis through several design changes, the Generation 1 (G-1), to the current design, the Generation 2. All arthroplasties in the present study were performed with the second generation device. All TKAs were performed via the medial parapatellar approach. Manipulation under anesthesia was performed for clinically significant arthrofibrosis and reduced range of motion as judged by individual surgeons.

Inclusion criteria were clinically significant osteoarthritis of the knee requiring a total knee replacement in patients over 18 years of age. Exclusion criteria were simultaneous bilateral procedures, BMI $>40$, fixed varus or valgus deformity $>15^{\circ}$, rheumatoid or other inflammatory arthritis, history of prior implant surgery on the treated knee, compromised posterior cruciate ligament (PCL) or collateral ligament, and osteoporosis.
Range of motion (ROM) and 2011 New Knee Society Scores (KSS) were evaluated preoperatively, and postoperatively at 6 weeks, 6 months, and annually thereafter. A paired t-test was used to compare pre-and postoperative results.

\section{RESULTS}

A total of 393 patients were offered participation in the study. 33 patients were excluded. (Table 1). 360 patients met eligibility criteria and agreed to participate, 154 male and 196 female. The mean patient age was 65.7 (range 4096). Mean BMI was 30.1 (range 18.5-42). The mean patient age and BMI for patients undergoing MUA was 61.7 and 28.5, respectively. Mean preoperative range of motion was $115^{\circ}$ (range $80-142^{\circ}$ ). A total of 298 patients had completed follow-up and outcome scores at one year, and 202 patients at 2 years.

Table 1: Excluded patients

\begin{tabular}{|l|c|}
\hline Reason & n \\
\hline BMI $>40$ & 2 \\
\hline Active Malignancy & 5 \\
\hline Simultaneous Bilateral TKA & 1 \\
\hline Osteoporosis & 3 \\
\hline Other physical disability of hip, spine, or contralateral knee & 1 \\
\hline Fixed coronal deformity $>15^{\circ}$ & 1 \\
\hline Fixed flexion deformity $>15^{\circ}$ & 2 \\
\hline Unwilling or unable to comply with study requirements & 14 \\
\hline Rheumatoid or other inflammatory arthropathy & 4 \\
\hline & \\
\hline Total & 33 \\
\hline
\end{tabular}

Preoperatively, ROM was $115^{\circ}\left(2^{\circ}\right.$ extension to $117^{\circ}$ flexion), and improved to $123^{\circ}\left(0^{\circ}\right.$ extension to $123^{\circ}$ flexion) in the entire cohort ( $\mathrm{p}<0.001)$. Prior to surgery, $43 \mathrm{pa}-$ tients demonstrated a flexion contracture, of these 29 were $1-5^{\circ}, 12$ were $6-10^{\circ}$, and $211-15^{\circ} .57$ patients had an extensor lag prior to surgery, 50 were $0-10^{\circ}$, and 7 were 10 $15^{\circ}$. At one year, 11 patients had a flexion contracture, 10 were $1-5^{\circ}$ and $111-15^{\circ}$. 6 patients had an extensor lag at one year, all were under $10^{\circ}$. All but two patients achieved $\mathrm{ROM}>90^{\circ}$ by one year, but both had ROM $>100^{\circ}$ at their 6 month visits.

A total of 11/360 patients (3.05\%) underwent MUA at an average of postoperative day 97 (Range 34-364). Of these patients, 8 were available for follow-up at one year, and 4 at two years. In patients who underwent MUA, ROM 
improved minimally at one year from the index procedure from $116^{\circ}\left(1^{\circ}\right.$ extension to $116^{\circ}$ flexion) to $117^{\circ}\left(-1^{\circ}\right.$ extension to $116^{\circ}$ flexion) $(\mathrm{p}=0.78)$. ROM averaged $86.3^{\circ}(65-$ 107) for these patients immediately prior to undergoing MUA, and improved to $117.1^{\circ}$ at the next scheduled visit.

Patients who underwent MUA, as well as patients in the entire cohort exhibited statistically significant $(\mathrm{p}<0.05)$ increases in KSS objective, functional, and satisfaction scores. (Tables 2 and 3) Expectation scores showed a slight decrease, but remained above the threshold for "met expectations." The MUA rate for centers with $>40$ patients enrolled was $2.4 \%$, whereas the MUA rate for centers with $<25$ patients enrolled was $6.0 \%$. No MUA was performed at $3 / 9$ centers (including 1 center that enrolled 29 patients). At 1 year, all but $2(99.2 \%)$ patients achieved functional range of motion $\left(>90^{\circ}\right)$.

Six patients have been revised at an average of 62 weeks. Four were polyethylene exchange for diagnoses of complex regional pain syndrome (CRPS), ligamentous laxity, infection, or scar tissue removal. None of these patients had previously undergone MUA, and all had range of motion of $105^{\circ}$ or greater at 6 months after the index procedure. Additionally, one revision was performed for a peri-prosthetic fracture, and another for metal hypersensitivity. Thus, there are three patients who have been converted to a different prosthesis in this study. Based on the last follow-up of all patients, the revision rate was $1.7 \%$ (6/360, including polyethylene exchanges) and survivorship was $99.2 \%$ at an average follow-up of 1.9 years.

Table 2: New Knee Society Scores for the entire cohort at 1 yr follow up $(n=278)$

\begin{tabular}{|l|c|c|c|c|c|}
\hline & Pre-op & 6-Week & 6-Month & 1-Year & $\begin{array}{c}\text { p (Preop } \\
\text { vs 1 yr) }\end{array}$ \\
\hline $\begin{array}{l}\text { Objective } \\
(0-100)\end{array}$ & 65 & 85 & 92 & 94 & $<0.001$ \\
\hline $\begin{array}{l}\text { Satisfaction } \\
(0-40)\end{array}$ & 14 & 25 & 31 & 34 & $<0.001$ \\
\hline $\begin{array}{l}\text { Expectations } \\
(0-15)\end{array}$ & 14 & 9 & 10 & 10 & $<0.001$ \\
\hline $\begin{array}{l}\text { Functional } \\
(0-100)\end{array}$ & 45 & 56 & 78 & 83 & $<0.001$ \\
\hline Pain (0-100) & 45 & 62 & 81 & 86 & $<0.001$ \\
\hline $\begin{array}{l}\text { Symptoms } \\
(0-100)\end{array}$ & 47 & 59 & 76 & 81 & $<0.001$ \\
\hline ADL (0-100) & 50 & 69 & 85 & 88 & $<0.001$ \\
\hline $\begin{array}{l}\text { Recreation } \\
(0-100)\end{array}$ & 19 & 36 & 59 & 69 & $<0.001$ \\
\hline QOL (0-100) & 18 & 45 & 65 & 72 & $<0.001$ \\
\hline ROM & 115 & 109 & 120 & 123 & $<0.001$ \\
\hline
\end{tabular}

\section{DISCUSSION}

The rationale for creating a patient-specific TKA is to improve clinical outcomes and patient satisfaction. [24] Described benefits over an "off the shelf" implant include lower incidence of blood transfusions and adverse events, improved tibial plateau coverage, and more normal femoral rollback. [25-27] However, a prior study on the first generation (G1) iTotal implant demonstrated a $28.6 \%$ rate of MUA. [23]

The present study demonstrates a MUA rate of $3.05 \%$ for the cruciate-retaining, second generation (G2) ConforMIS iTotal implant, which is similar to rates reported throughout the literature, irrespective of implant design. [2-7] Additionally, patients overall achieved functional range of motion $\left(>90^{\circ}\right)$ at 1 year, including patients who underwent MUA. Although White et al. reported a markedly higher rate of MUA with a patient-specific design, the current findings are similar to data presented by Kurtz et al demonstrating a 3.8\% incidence of MUA at 90 days with the ConforMIS G1 implant. [28] The difference in MUA rate in the present study compared to the White et al paper may be the result of design changes, or potentially due to the comparisons of one surgeon versus nine surgeons in nine centers.

The rate of MUA varied across institutions from 0-9\%, with $3 / 9$ centers reporting no manipulations. Centers with $<25$ patients enrolled reported a higher average manipulation rate $(6.0 \%)$, versus those with $>40$ patients $(2.4 \%)$

Table 3: New Knee Society Scores for patients undergoing MUA at 1 yr follow up $(n=8)$

\begin{tabular}{|l|c|c|c|c|c|}
\hline & Pre-op & 6-Week & 6-Month & 1-Year & $\begin{array}{c}\text { p (Preop } \\
\text { vs 1 yr) }\end{array}$ \\
\hline $\begin{array}{l}\text { Objective } \\
(0-100)\end{array}$ & 57 & 75 & 83 & 92 & 0.021 \\
\hline $\begin{array}{l}\text { Satisfaction } \\
(0-40)\end{array}$ & 9 & 20 & 24 & 29 & 0.007 \\
\hline $\begin{array}{l}\text { Expectations } \\
(0-15)\end{array}$ & 14 & 7 & 9 & 10 & 0.051 \\
\hline $\begin{array}{l}\text { Functional } \\
(0-100)\end{array}$ & 41 & 46 & 72 & 74 & 0.015 \\
\hline Pain (0-100) & 38 & 53 & 74 & 76 & 0.010 \\
\hline $\begin{array}{l}\text { Symptoms } \\
(0-100)\end{array}$ & 43 & 46 & 63 & 70 & 0.028 \\
\hline ADL (0-100) & 45 & 61 & 80 & 81 & 0.009 \\
\hline $\begin{array}{l}\text { Recreation } \\
(0-100)\end{array}$ & 11 & 25 & 54 & 64 & 0.001 \\
\hline QOL (0-100) & 14 & 30 & 53 & 55 & 0.007 \\
\hline ROM & 112 & 84 & 113 & 117 & 0.780 \\
\hline
\end{tabular}


This may indicate that factors associated with higher MUA rates may include surgeon volume and experience with the patient-specific implant. However, a recent registry analysis of 59,696 TKAs found no association with volume and MUA. [29]

In addition to a lower manipulation rate, the present study also demonstrated good patient-reported outcomes. Across the entire cohort, patients reported statistically significant improvements in all KSS outcome measures with the exception of the expectation score. Pre-operatively, patients reported high expectations (expectation score of 14/15) for the surgical procedure. At the 6 week postoperative visit patient expectations had dropped, but on average patients reported the surgery to have met expectations (9/15, with 9 being the threshold for "met expectations"). By the 6 month visit, patient expectations had improved from the 6 week time point, with patients on average reporting the procedure to have marginally exceeded expectations (10/15). Throughout the current literature, patients often report unmet expectations after total knee arthroplasty, possibly due to excessive optimism about results. [3032] A prior study using the $2011 \mathrm{KSS}$ to evaluate TKA outcomes found that although patient satisfaction and all other scores improved after surgery, the expectation score decreased slightly, leading researchers to postulate that patients may be satisfied after TKA in different ways than expected. [33] Additionally, it is possible that patients receiving a patient specific design may have higher expectations for their outcomes as opposed to those who receive a conventional implant. An earlier study showed a high dissatisfaction rate $(11.1 \%)$ with the earlier, G1 version of the iTotal implant. [23] However, the present study found that only $6 / 298$ (2.0\%) of patients reported being "dissatisfied" or "very dissatisfied" with their results at 1 year (KSS satisfaction score $<10$ ), with an average KSS satisfaction score of 34 in the entire study. This compares favorably with the existing literature, which reports overall patient satisfaction rates of $81-89 \%$, as well as KSS satisfaction scores of 23-38 for primary TKA. $[\underline{33}, \underline{34}, \underline{43}-\underline{52}, \underline{35}-\underline{42}]$ Revision surgery was rare, with only $1.7 \%$ (6/360) patients requiring revision surgery within 2 years. Three of these patients continue to have the device, yielding an implant survivorship of $99.2 \%$.

Limitations to this study include a lack of standardized indications for undergoing MUA and incomplete follow up (298 of 360 patients at 1 years, including 8 of 11 patients who underwent MUA). However, patients who did not complete 1 year follow up did not report problems that would be indications for MUA at the 6 week or 6 month visit. Thus, it is unlikely that additional patients in the study will require MUA in the future. Strengths of the study include the size of the cohort (360 patients). Additionally, all patients in the study were prospectively recruited at 9 centers, thus providing a more robust estimate of expected MUA rates after surgery with the second generation iTotal CR device as compared to single center experiences.

In conclusion, the present study demonstrates an acceptable rate of MUA in a large cohort of patients who underwent TKA with the ConforMIS G2 iTotal CR patientspecific TKA. Additionally, patient reported outcomes demonstrated significant improvements in pain, function, and satisfaction. Further follow-up continues at all sites. Data from longer term follow-up on the entire cohort as well as the patients that experienced MUAs in this study population will provide a deeper understanding of overall survival, patient outcomes and long term effects of MUA on patients receiving this device.

\section{References}

1. Cheuy VA, Foran JRH, Paxton RJ, Bade MJ, Zeni JA, Stevens-Lapsley JE. Arthrofibrosis Associated With Total Knee Arthroplasty. J Arthroplasty [Internet]. 2017 Aug [cited 2017 Aug 31];32(8):2604-11. Available from: http://linkinghub.elsevier.com/retrieve/pii/S0883540317301043

2. Namba RS, Inacio M. Early and late manipulation improve flexion after total knee arthroplasty. J Arthroplasty [Internet]. 2007 Sep [cited 2017 Aug 31];22(6 Suppl 2):58-61. Available from: http://linkinghub.elsevier.com/retrieve/pii/ S0883540307001222

3. Werner BC, Carr JB, Wiggins JC, Gwathmey FW, Browne JA. Manipulation Under Anesthesia After Total Knee Arthroplasty is Associated with An Increased Incidence of Subsequent Revision Surgery. J Arthroplasty [Internet]. 2015 Sep [cited 2017 Aug 31];30(9 Suppl):72-5. Available from: http://linkinghub.elsevier.com/ retrieve/pii/S0883540315004738

4. Bawa HS, Wera GD, Kraay MJ, Marcus RE, Goldberg VM. Predictors of range of motion in patients undergoing manipulation after TKA. Clin Orthop Relat Res [Internet]. 2013 Jan 12 [cited 2017 Aug 31];471(1):258-63. Available from: http:// link.springer.com/10.1007/s11999-012-2591-1

5. Cates HE, Schmidt JM. Closed manipulation after total knee arthroplasty: outcome and affecting variables. Orthopedics [Internet]. 2009 Jun 1 [cited 2017 Aug 31];32(6):398. Available from: http://www.healio.com/doiresolver?d oi $=10.3928 / 01477447-20090511-10$

6. Keating EM, Ritter MA, Harty LD, Haas G, Meding JB, Faris PM, et al. Manipulation after total knee arthroplasty. J Bone Joint Surg Am [Internet]. 2007 Feb 1 [cited 2017 Aug 31];89(2):282-6. Available from: http://jbjs.org/cgi/doi/10.2106/ JBJS.E.00205

7. Pfefferle KJ, Shemory ST, Dilisio MF, Fening SD, Gradisar IM. Risk factors for manipulation after total knee arthroplasty: a pooled electronic health record database study. J Arthroplasty [Internet]. 2014 Oct [cited 2017 Aug 31];29(10):2036-8 Available from: http://linkinghub.elsevier.com/retrieve/pii/S0883540314003088

8. Fitzsimmons SE, Vazquez EA, Bronson MJ. How to treat the stiff total knee arthroplasty?: a systematic review. Clin Orthop Relat Res [Internet]. 2010 Apr 20 [cited 2017 Aug 31];468(4):1096-106. Available from: http://link.springer. com/10.1007/s11999-010-1230-y

9. Issa K, Banerjee S, Kester MA, Khanuja HS, Delanois RE, Mont MA. The Effect of Timing of Manipulation Under Anesthesia to Improve Range of Motion and Functional Outcomes Following Total Knee Arthroplasty. J Bone Jt Surg [Internet]. 2014 Aug 20 [cited 2017 Sep 13];96(16):1349-57. Available from: http:// www.ncbi.nlm.nih.gov/pubmed/25143495

10. Vun SH, Shields DW, Sen A, Shareef S, Sinha S, Campbell AC. A national questionnaire survey on knee manipulation following total knee arthroplasty. J Orthop [Internet]. 2015 Dec [cited 2017 Aug 31];12(4):193-6. Available from: http://linkinghub.elsevier.com/retrieve/pii/S0972978X15000835

11. Pivec R, Issa K, Kester M, Harwin SF, Mont MA. Long-term outcomes of MUA for stiffness in primary TKA. J Knee Surg [Internet]. 2013 Dec 19 [cited 2017 Aug 31];26(6):405-10. Available from: http://www.thieme-connect.de/DOI/ 
DOI?10.1055/s-0033-1341579

12. Mohammed R, Syed S, Ahmed N. Manipulation under anaesthesia for stiffness following knee arthroplasty. Ann R Coll Surg Engl [Internet]. 2009 Apr [cited 2017 Sep 13];91(3):220-3. Available from: http://publishing.rcseng.ac.uk/ doi/10.1308/003588409X359321

13. Pariente GM, Lombardi A V, Berend KR, Mallory TH, Adams JB. Manipulation with prolonged epidural analgesia for treatment of TKA complicated by arthrofibrosis. Surg Technol Int [Internet]. 2006 [cited 2017 Sep 13];15:221-4. Available from: http://www.ncbi.nlm.nih.gov/pubmed/17029180

14. Stephenson JJ, Quimbo RA, Gu T. Knee-attributable medical costs and risk of resurgery among patients utilizing non-surgical treatment options for knee arthrofibrosis in a managed care population. Curr Med Res Opin [Internet]. 2010 May 15 [cited 2017 Aug 31];26(5):1109-18. Available from: http://www.tandfonline.com/ doi/full/10.1185/03007991003676479

15. Kotani A, Yonekura A, Bourne RB. Factors influencing range of motion after contemporary total knee arthroplasty. J Arthroplasty [Internet]. 2005 Oct [cited 2017 Aug 31];20(7):850-6. Available from: http://linkinghub.elsevier.com/retrieve/pii/ S0883540305000203

16. Ghani H, Maffulli N, Khanduja V. Management of stiffness following total knee arthroplasty: a systematic review. Knee [Internet]. 2012 Dec [cited 2017 Aug 31];19(6):751-9. Available from: http://linkinghub.elsevier.com/retrieve/pii/ S0968016012000397

17. Magit D, Wolff A, Sutton K, Medvecky MJ. Arthrofibrosis of the knee. J Am Acad Orthop Surg [Internet]. 2007 Nov [cited 2017 Aug 31];15(11):682-94. Available from: http://www.ncbi.nlm.nih.gov/pubmed/17989419

18. Haller JM, Holt DC, McFadden ML, Higgins TF, Kubiak EN. Arthrofibrosis of the knee following a fracture of the tibial plateau. Bone Joint J [Internet]. 2015 Jan 1 [cited 2017 Aug 31];97-B(1):109-14. Available from: http://www.bjj.boneandjoint.org.uk/cgi/doi/10.1302/0301-620X.97B1.34195

19. Chaudhary R, Beaupré LA, Johnston DWC. Knee range of motion during the first two years after use of posterior cruciate-stabilizing or posterior cruciateretaining total knee prostheses. A randomized clinical trial. J Bone Joint Surg Am [Internet]. 2008 Dec [cited 2017 Aug 31];90(12):2579-86. Available from: http://content.wkhealth.com/linkback/openurl?sid=WKPTLP:landingpage\& an $=00004623-200812000-00002$

20. Issa K, Rifai A, Boylan MR, Pourtaheri S, McInerney VK, Mont MA. Do various factors affect the frequency of manipulation under anesthesia after primary total knee arthroplasty? Clin Orthop Relat Res [Internet]. 2015 Jan 8 [cited 2017 Aug 31];473(1):143-7. Available from: http://link.springer.com/10.1007/s11999014-3772-X

21. Bercik MJ, Joshi A, Parvizi J. Posterior cruciate-retaining versus posterior-stabilized total knee arthroplasty: a meta-analysis. J Arthroplasty [Internet]. 2013 Mar [cited 2017 Aug 31];28(3):439-44. Available from: http://linkinghub.elsevier. com/retrieve/pii/S0883540312005773

22. Rubinstein RA, DeHaan A. The incidence and results of manipulation after primary total knee arthroplasty. Knee [Internet]. 2010 Jan [cited 2017 Aug 31];17(1):29-32. Available from: http://linkinghub.elsevier.com/retrieve/pii/ S0968016009001173

23. White PB, Ranawat AS. Patient-Specific Total Knees Demonstrate a Higher Manipulation Rate Compared to "Off-the-Shelf Implants". J Arthroplasty [Internet]. 2016 Jan [cited 2017 Aug 31];31(1):107-11. Available from: http://linkinghub.elsevier.com/retrieve/pii/S0883540315007196

24. Schwechter EM, Fitz W. Design rationale for customized TKA: a new idea or revisiting the past? Curr Rev Musculoskelet Med [Internet]. 2012 Dec 27 [cited 2017 Sep 7];5(4):303-8. Available from: http://link.springer.com/10.1007/ s12178-012-9143-x

25. Patil S, Bunn A, Bugbee WD, Colwell CW, D'Lima DD. Patient-specific implants with custom cutting blocks better approximate natural knee kinematics than standard TKA without custom cutting blocks. Knee [Internet]. 2015 Dec [cited 2017 Sep 7];22(6):624-9. Available from: http://www.ncbi.nlm.nih.gov/ pubmed/27092379

26. Martin G. In-vivo tibial fit analysis of patient specific TKA system versus off-theshelf TKA. JISRF Reconstr Rev. 2014;4(102).

27. Martin G, Swearingen A, Culler S. Hospital Outcomes and Cost for Patients Undergoing a Customized Individually Made TKA vs Off-The-Shelf TKA. JISRF Reconstr [Internet]. 2014 [cited 2017 Sep 7];4(103). Available from: https://www. implan-tec.ch/sites/default/files/upload/ConforMIS Publikationen/MK-02956AA_Hospital Outcomes (Culler).pdf

28. Kurtz W, Sinha R, Martin G, Kimball K. Early Outcomes Utilizing a First-Generation Customized Patient-Specific TKA Implant. In: British Association for Surgery of the Knee. Norwich; 2014.

29. Pamilo KJ, Peltola M, Paloneva J, Mäkelä K, Häkkinen U, Remes V. Hospital volume affects outcome after total knee arthroplasty. Acta Orthop [Internet].
2015;86(1):41-7. Available from: http://www.tandfonline.com/doi/full/10.3109/1 7453674.2014.977168

30. Suda AJ, Seeger JB, Bitsch RG, Krueger M, Clarius M. Are patients' expectations of hip and knee arthroplasty fulfilled? A prospective study of 130 patients. Orthopedics [Internet]. 2010 Feb 1 [cited 2017 Sep 7];33(2):76-80. Available from: http://www.healio.com/doiresolver?doi=10.3928/01477447-20100104-07

31. Scott CEH, Bugler KE, Clement ND, MacDonald D, Howie CR, Biant LC. Patient expectations of arthroplasty of the hip and knee. J Bone Joint Surg Br [Internet]. 2012 Jul 1 [cited 2017 Sep 7];94(7):974-81. Available from: http://www.bjj.boneandjoint.org.uk/cgi/doi/10.1302/0301-620X.94B7.28219

32. Mannion AF, Kämpfen S, Munzinger U, Kramers-de Quervain I. The role of patient expectations in predicting outcome after total knee arthroplasty. Arthritis Res Ther [Internet]. 2009 [cited 2017 Sep 7];11(5):R139. Available from: http://arthritis-research.biomedcentral.com/articles/10.1186/ar2811

33. Kuroda Y, Matsumoto T, Takayama K, Ishida K, Kuroda R, Kurosaka M. Subjective evaluation before and after total knee arthroplasty using the 2011 Knee Society Score. Knee [Internet]. 2016 Dec [cited 2017 Oct 17];23(6):964-7. Available from: http://www.ncbi.nlm.nih.gov/pubmed/27802922

34. Bourne RB, Chesworth BM, Davis AM, Mahomed NN, Charron KDJ. Patient satisfaction after total knee arthroplasty: who is satisfied and who is not? Clin Orthop Relat Res [Internet]. 2010 Jan [cited 2017 Sep 13];468(1):57-63. Available from: http://www.ncbi.nlm.nih.gov/pubmed/19844772

35. Anderson JG, Wixson RL, Tsai D, Stulberg SD, Chang RW. Functional outcome and patient satisfaction in total knee patients over the age of 75. J Arthroplasty [Internet]. 1996 Oct [cited 2017 Sep 13];11(7):831-40. Available from: http://www. ncbi.nlm.nih.gov/pubmed/8934323

36. Chesworth BM, Mahomed NN, Bourne RB, Davis AM, OJRR Study Group. Willingness to go through surgery again validated the WOMAC clinically important difference from THR/TKR surgery. J Clin Epidemiol [Internet]. 2008 Sep [cited 2017 Sep 13];61(9):907-18. Available from: http://www.ncbi.nlm.nih.gov/ pubmed/18687289

37. Dunbar MJ, Robertsson O, Ryd L, Lidgren L. Appropriate questionnaires for knee arthroplasty. Results of a survey of 3600 patients from The Swedish Knee Arthroplasty Registry. J Bone Joint Surg Br [Internet]. 2001 Apr [cited 2017 Sep 13];83(3):339-44. Available from: http://www.ncbi.nlm.nih.gov/ pubmed/11341416

38. Hawker G, Wright J, Coyte P, Paul J, Dittus R, Croxford R, et al. Health-related quality of life after knee replacement. J Bone Joint Surg Am [Internet]. $1998 \mathrm{Feb}$ [cited 2017 Sep 13];80(2):163-73. Available from: http://www.ncbi.nlm.nih.gov/ pubmed/9486722

39. Heck DA, Robinson RL, Partridge CM, Lubitz RM, Freund DA. Patient outcomes after knee replacement. Clin Orthop Relat Res [Internet]. 1998 Nov [cited 2017 Sep 13];(356):93-110. Available from: http://www.ncbi.nlm.nih.gov/ pubmed/9917673

40. Noble PC, Conditt MA, Cook KF, Mathis KB. The John Insall Award: Patient Expectations Affect Satisfaction with Total Knee Arthroplasty. Clin Orthop Relat Res [Internet]. $2006 \mathrm{Nov}$ [cited 2017 Sep 13];452:35-43. Available from: http://www. ncbi.nlm.nih.gov/pubmed/16967035

41. Robertsson O, Dunbar M, Pehrsson T, Knutson K, Lidgren L. Patient satisfaction after knee arthroplasty: A report on 27,372 knees operated on between 1981 and 1995 in Sweden. Acta Orthop Scand [Internet]. 2000 Jan 8 [cited 2017 Sep 13];71(3):262-7. Available from: http://www.ncbi.nlm.nih.gov/pubmed/10919297

42. Wylde V, Learmonth I, Potter A, Bettinson K, Lingard E. Patient-reported outcomes after fixed- versus mobile-bearing total knee replacement: A MULTI-CENTRE RANDOMISED CONTROLLED TRIAL USING THE KINEMAX TOTAL KNEE REPLACEMENT. J Bone Jt Surg - Br Vol [Internet]. 2008 Sep 1 [cited 2017 Sep 13];90-B(9):1172-9. Available from: http://www.ncbi.nlm.nih.gov/ pubmed/18757956

43. Matsuda S, Kawahara S, Okazaki K, Tashiro Y, Iwamoto Y. Postoperative Alignment and ROM Affect Patient Satisfaction After TKA. Clin Orthop Relat Res [Internet]. 2013 Jan 18 [cited 2017 Dec 5];471(1):127-33. Available from: http://link. springer.com/10.1007/s11999-012-2533-y

44. Nakahara H, Okazaki K, Mizu-uchi H, Hamai S, Tashiro Y, Matsuda S, et al. Correlations between patient satisfaction and ability to perform daily activities after total knee arthroplasty: why aren't patients satisfied? J Orthop Sci [Internet]. 2015 [cited 2017 Dec 5];20:87-92. Available from: https://www.clinicalkey.com/ service/content/pdf/watermarked/1-s2.0-S0949265815301627.pdf?locale=en_US

45. Furu M, Ito H, Nishikawa T, Nankaku M, Kuriyama S, Ishikawa M, et al. Quadriceps strength affects patient satisfaction after total knee arthroplasty. 2015 [cited 2017 Dec 5]; Available from: https://www.clinicalkey.com/service/content/pdf/ watermarked/1-s2.0-S0949265815000652.pdf?locale=en_US

46. Nakano N, Matsumoto T, Ishida K, Tsumura N, Kuroda R, Kurosaka M. Longterm subjective outcomes of computer-assisted total knee arthroplasty. Int Orthop 
[Internet]. 2013 Oct [cited 2017 Dec 5];37(10):1911-5. Available from: http:// www.ncbi.nlm.nih.gov/pubmed/23807729

47. Kawahara S, Okazaki K, Matsuda S, Nakahara H, Okamoto S, Iwamoto Y. Internal Rotation of Femoral Component Affects Functional Activities After TKA-Survey With The 2011 Knee Society Score. J Arthroplasty [Internet]. 2014 Dec [cited 2017 Dec 5];29(12):2319-23. Available from: http://linkinghub.elsevier.com/retrieve/pii/S0883540313008620

48. Wada O, Nagai K, Hiyama Y, Nitta S, Maruno H, Mizuno K. Diabetes is a Risk Factor for Restricted Range of Motion and Poor Clinical Outcome After Total Knee Arthroplasty. J Arthroplasty [Internet]. 2016 Sep [cited 2017 Dec 5];31(9):1933-7. Available from: http://linkinghub.elsevier.com/retrieve/pii/S0883540316001820

49. Conjeski JM, Scuderi GR. Lateral Femoral Epicondylar Osteotomy for Correction of Fixed Valgus Deformity in Total Knee Arthroplasty: A Technical Note. J Arthroplasty [Internet]. 2017 Sep [cited 2017 Dec 5]; Available from: http://linkinghub. elsevier.com/retrieve/pii/S0883540317308021

50. Choi NY, In Y, Bae J-H, Do J-H, Chung SJ, Koh IJ. Are Midterm Patient-Reported Outcome Measures Between Rotating-Platform Mobile-Bearing Prosthesis and Medial-Pivot Prosthesis Different? A Minimum of 5-Year Follow-Up Study. J Arthroplasty [Internet]. 2017 Mar [cited 2017 Dec 5];32(3):824-9. Available from: http://linkinghub.elsevier.com/retrieve/pii/S0883540316305757

51. Meneghini RM, Grant TW, Ishmael MK, Ziemba-Davis M. Leaving Residual Varus Alignment After Total Knee Arthroplasty Does Not Improve Patient Outcomes. J Arthroplasty [Internet]. 2017 Sep [cited 2017 Dec 5];32(9):S171-6. Available from: http://linkinghub.elsevier.com/retrieve/pii/S0883540317301821

52. Warth LC, Ishmael MK, Deckard ER, Ziemba-Davis M, Meneghini RM. Do Medial Pivot Kinematics Correlate With Patient-Reported Outcomes After Total Knee Arthroplasty? J Arthroplasty [Internet]. 2017 Aug [cited 2017 Dec 5];32(8):2411-6. Available from: http://linkinghub.elsevier.com/retrieve/pii/ S0883540317302218
SUBMISSION HISTORY

Submitted August 15, 2018

Reviewed September 15, 2018

Accepted September 20, 2018

Published September 30, 2018

\section{AUTHOR AFFILIATIONS}

1 Andrew Brecher Kay, MD; Terry A Clyburn, MD

Houston Methodist Hospital, 6565 Fannin St., Houston, TX 77030

2 William B Kurtz, MD

Tennessee Orthopedic Alliance, 8 City Blvd. (West End/Charlotte Ave.), Nashville, TN 37209

3 Gregory M Martin, MD

JFK Medical Center North Campus, 2201 45th St, West Palm Beach, FL 33407

4 Bryan M Huber, MD Mansfield Orthopaedics, 555 Washington Hwy, Morrisville, VT 05661

5 Robert J Tait, MD Ortho Institute of Henderson, 10561 Jeffrey's St. Suite 230, Henderson, NV 89052 (Direct inquires to Andrew Brecher Kay, drandykay@gmail.com)

AUTHOR DISCLOSURES

Andrew Kay declares that there are no disclosures regarding the publication of this paper. All other authors declare either their family, institutions they are associated with, or themselves have received benefits or funds either directly or indirectly regarding this article.

\section{COPYRIGHT \& OPEN ACCESS}

(C) 2018 Minter. All rights reserved.

Authors retain copyright and grant the journal right of first publication with the work. Reconstructive Review is an open access publication and follows the Creative Commons Attribution-NonCommercial CC BY-NC. This

license allows anyone to download works, build upon the material, and share them with others for non-commercial purposes as long as they credit the senior author, Reconstructive Review, and the Joint Implant Surgery \& Research Foundation (JISRF). An example credit would be: "Courtesy of (senior author's name), Reconstructive Review, JISRF, Chagrin Falls, Ohio". 